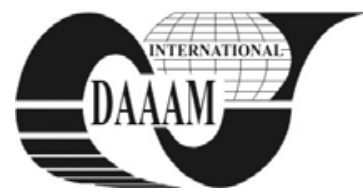

Annals of DAAAM for 2011 \& Proceedings of the 22nd International DAAAM Symposium, Volume 22, No. 1, ISSN 1726-9679 ISBN 978-3-901509-83-4, Editor B. Katalinic, Published by DAAAM International, Vienna, Austria, EU, 2011 Make Harmony between Technology and Nature, and Your Mind will Fly Free as a Bird Annals \& Proceedings of DAAAM International 2011

\title{
MODIFICATION OF CONSTRUCTION DESIGN OF VERTICAL AXIS WIND TURBINE
}

\author{
KACOR, P[etr]; MISAK, S[tanislav] \& PROKOP, L[ukas]
}

\begin{abstract}
Paper deals with one of the possibility how to improve the basic design of vertical axis wind turbine (VAWT) from the view of optimal output parameters. CFD (Computer Fluid Dynamics) software is used to complex analysis of wind turbine in two operation cases. Steady-state simulation serves for estimating of locked-rotor torque. Outputs of transient simulation determine driving torques for selected values of rotation speed of rotor. The both types of analyses are utilized for estimating of basic dimensions of design of vertical axis wind turbines.
\end{abstract}

Key words: VAWT, wind turbine, CFD simulation, rotor torque, transient analysis

\section{INTRODUCTION}

Wind turbines with a horizontal axis of rotation (HAWT) currently represent the most common design of wind power stations for generating of electric power. The output power from HAWT is relative wide in ranges from $1 \mathrm{~kW}$ to units of MW. Although the type of construction of these kinds of wind power plants is various there can be found several factors that are common for proper functionality of HAWT. (Manwell et al., 2009; Patel, 1999) In particular, the higher wind velocity is typical for optimal operation of HAWT and related to that the necessity to use the equipment for suitable adjustment of turbine blades against direction of wind. (Paraschivoiu, 2002; Eriksson, 2008) If the wind velocity is low, the HAWT efficiency is also low and the wind power plant is not fully utilized.

In the areas that are distinguished by lower wind velocities it is more appropriate to use of the vertical axis wind turbine (VAWT). The output power from VAWT is usually lower and in ranges from hundreds of $\mathrm{W}$ to units of $\mathrm{kW}$. The main advantages of VAWT includes especially the independence of wind direction and operation at low wind velocities. There is also no need to use complex and costly equipment for blade adjusting and setup. The entire system of VAWT can form, for example, the part of street lighting systems or to serve as an autonomous electric power source. (Kacor et al.,2010) The design of the power plant with vertical rotor arrangement is less complicated compared with HAWT and there is also high reliability of the whole system.

This paper deals with the possibility of applying numerical methods for finding-out the optimal design of VAWT. The results of the performed simulation serve for determination of the most appropriate dimensions and parameters needed for the real wind turbine design.

\section{THE ORIGINAL DESIGN OF VAWT}

In the campus of VŠB-Technical University in Ostrava city the VAWT with the H-rotor is operated which is part of a hybrid power supply unit for a public lighting system. Our VAWT has 5 vertical blades that are equally arranged around the axis of rotation. Rotor diameter is $\mathrm{D}=800 \mathrm{~mm}$ and blades length is $\mathrm{L}=1500 \mathrm{~mm}$. Blades have the shape corresponding to the aerodynamic wing profile. Fig. 1 shows the basic VAWT design and also the cross-section across the middle part of the rotor blades.
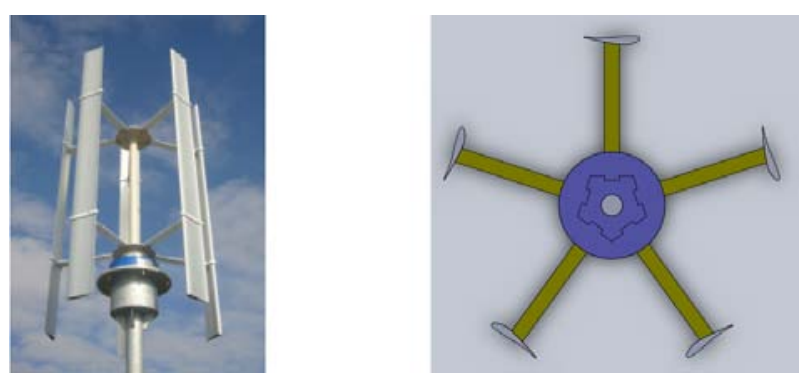

Fig. 1. VAWT construction design and CAD model

As the test measurements and performed numerical simulations of the original VAWT design from Fig. 1 confirmed, the manufacturer's parameters are far from the real ones. The turbine provides roughly $1 / 10$ of nominal output $-\mathrm{P}_{\mathrm{N}}$ at nominal wind velocity $-\mathrm{v}_{\mathrm{W}}=10 \mathrm{~m} / \mathrm{s}$. Due to the type of driven generator the output of VAWT is insufficient. Moreover, when comparing the design of our VAWT with similar designs of other manufacturers we see that for this machine type there are most frequently design options with a larger rotor diameter and shorter length of blades.

\subsection{CFD Analysis of Original WAVT Design}

The basic tool for analyzing the wind turbine is the software that enables to solve the air flow around machine blades. There are currently a number of free (OpenFOAM, Free CFD) as well as commercial (ANSYS, CFX, FLUENT) CFD codes that can be used for this.

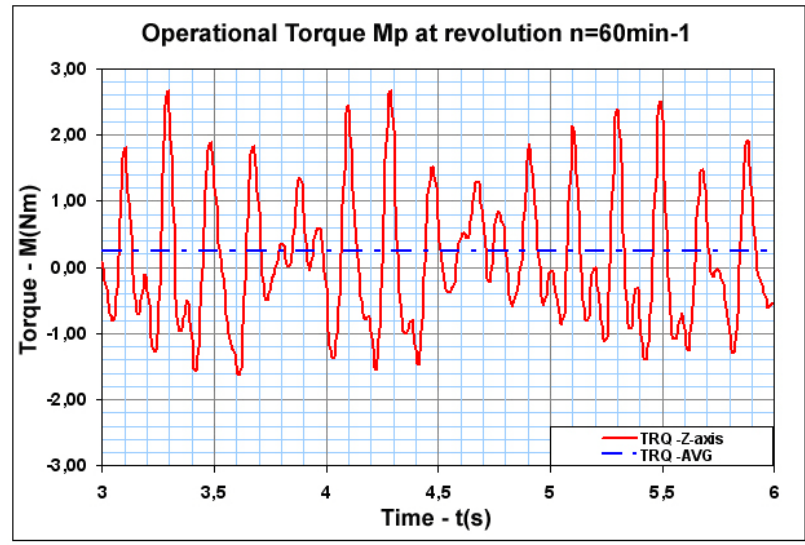

Fig. 2. VAWT Operational torque at constant revolution

Fig. 2 shows the behaviour of operational torque $-\mathrm{M}_{\mathrm{p}}$ of the original VAWT at constant revolutions $n=60 \mathrm{~min}^{-1}$ obtained from a transient analysis. There was selected the time interval $T_{X}=(3 \div 6)$ s for examination of torque dependence in which the 
air flow from the leading edge of turbine is already steady and the change of pressure and velocity conditions only take place by blade rotation. As can be seen from this Fig. 2 very strong pulsation of operational torque - $\mathrm{M}_{\mathrm{P}}$ occurs. The range of torque moves around values $-\mathrm{M}_{\mathrm{p}}=(-1.62 \div 2.6) \mathrm{Nm}$. The value of $\mathrm{M}_{\mathrm{PAVG}}=0.21 \mathrm{Nm}$ corresponds to average value of operational torque.

\section{DESIGN OF MULTI-BLADES TURBINE}

A multi-blade rotor with external diffusion ring (stator blades) became the basis of the new wind motor design. The basic form of the new turbine design is based on the Lafond turbine. Several options were considered during the design process. To give you a better idea of individual Options A and $\mathrm{B}$, they are shown at Fig. 3 .

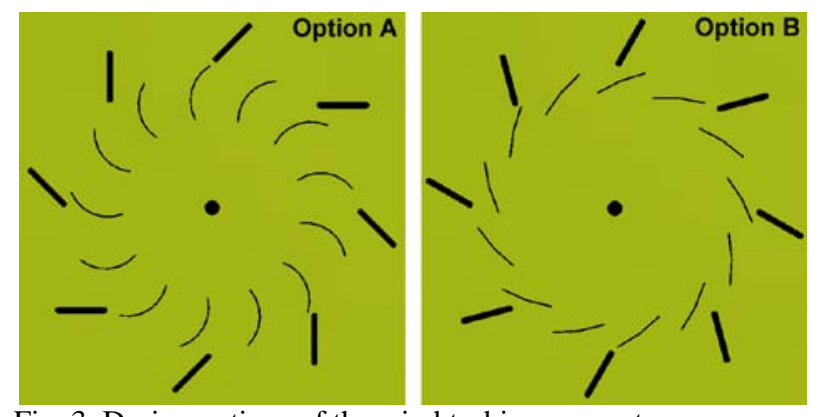

Fig. 3. Design options of the wind turbine concept

\subsection{CFD Analysis of the New Designed Turbines}

Fig. 4 shows the comparison of speed conditions of design Options A an B. At Option A the air flow enters through stator blades inside the rotor where it increases its speed due to profile (channel) narrowing with circulating blades.

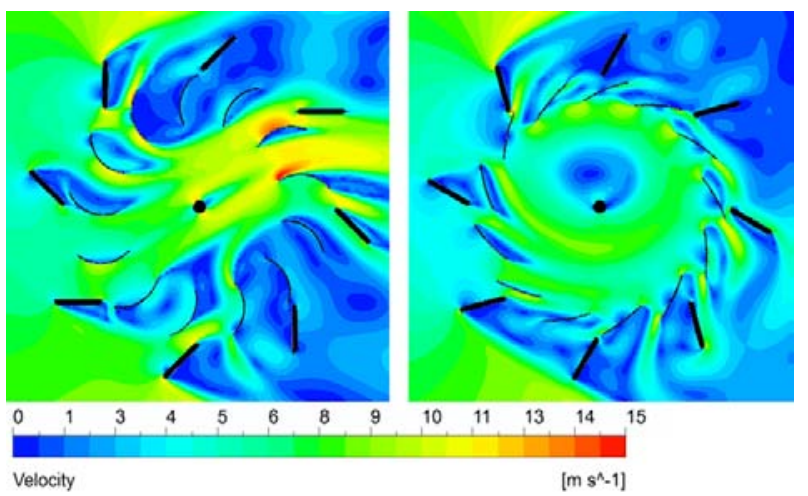

Fig. 4. Velocity distribution for the CFD of Options A and B

For Option B the situation is quite different. Significant deformation of air flow occurs through appropriate adjusting of the angle of stator blades and circular rotor blades. After the wind enters into rotor, concentrates on its inner diameter where it then rotates with greater speed than the circumferential speed of rotor blades. Then 10 blades of the total 13 create a driving force and the turbine starting torque.

Fig. 5 shows the behavior of operational torque $-M_{P}$ of Options A and B at constant revolutions $n=60 \mathrm{~min}^{-1}$. Option A shows higher torque values but at the same time also with higher pulsation and amplitude $\mathrm{M}_{\mathrm{P}}=(1.8 \div 4.4) \mathrm{Nm}$. Option $\mathrm{B}$ reaches lower torque values but its behavior is practically constant. For option A the mean value of operational torque is $\mathrm{M}_{\mathrm{PAAVG}}=3.2 \mathrm{Nm}$ and for Option $\mathrm{B}$ is $\mathrm{M}_{\mathrm{PBAVG}}=1.8 \mathrm{Nm}$ i.e. approximately half.

For determining of turbine output power we apply the standard equation (relation) of the product of mechanical torque and angular velocity. Selected value of speed revolution $\mathrm{n}=60 \mathrm{~min}^{-1}$ is not nominal and thus the result values of operational torque $-\mathrm{M}_{\mathrm{P}}$ and other outputs need to be understood as a comparative criterion and not the final values.

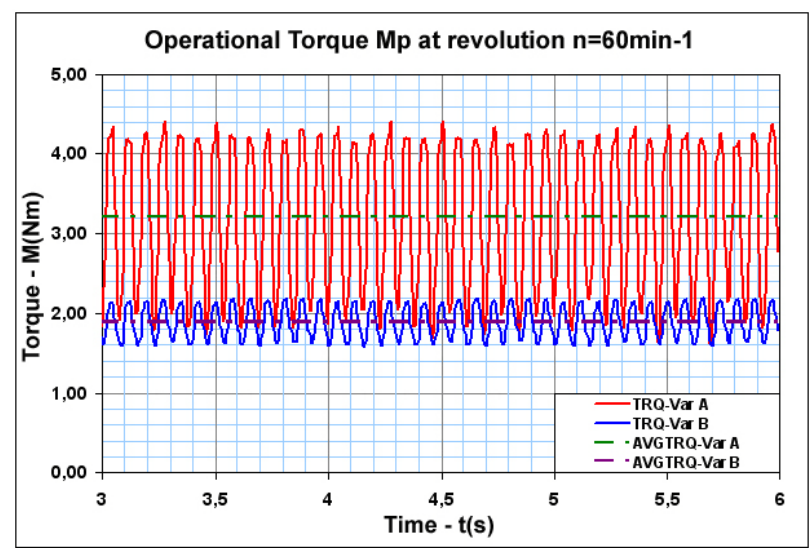

Fig. 5. Operational torque at constant revolution $n=60 \mathrm{~min}-1$

\section{CONCLUSION}

This paper presents the possibilities of using of CFD software for the analysis of a wind turbine with a vertical axis of rotation. An indisputable benefit of CFD simulation is the fact that various options and construction modifications of wind turbine can be analyzed on numerical models without real construction of sample. If we also know the generator characteristics, the output power characteristics of the entire power plant can be easily determined by using a graphicalcomputing method.

At present time there is realized the real construction of the testing sample of turbine by dimensions of Option B design. Next step will be the laboratory measurement of output power characteristic of realized wind turbine in connection with synchronous generator. So at this time the monitoring of overall functionality of the wind power plant system is also being prepared.

Future research lies in finding out of optimal shape and numbers of rotor blades for higher efficiency of whole system.

\section{ACKNOWLEDGEMENTS}

This work was supported by the Ministry of Education, Youth and Sports of the Czech Republic (ENET No. CZ.1.05/2.1.00/03.0069) and project MSM 6198910007 and also project SP2011/130.

\section{REFERENCES}

Eriksson, S. (2008). Direct Driven Generator for Vertical Axis Wind Turbines, Acta Universitatis Upsaliensis, ISBN 97891-554-7264-1, Uppsala, Sweden

Kacor, P.; Misak, S. \& Prokop, L. (2010). Optimization and Redesign of Vertical Axis Wind Turbine for Generator of Independent Source of Energy, Annals of DAAAM for 2010 \& Proceedings of the 21st International DAAAM Symposium, 20-23rd October 2010, Zadar, Croatia, ISSN 1726-9679, ISBN 978-3-901509-73-5, Katalinic, B. (Ed.), pp. 1053-1054, Published by DAAAM International Vienna, Vienna

Manwell, J.; McGowan, J. \& Rogers, A. (2009). Wind Energy Explained: Theory, Design and Application, John Wiley \& Sons, ISBN 978-0-470-01500-1, New York

Paraschivoiu, I. (2002). Wind Turbine Design with Emphasis on Darrieus Concept, John Wiley \& Sons, ISBN 2-55300931-3, New York

Patel, M. R. (1999). Wind and Solar Power Systems, CRC Press, ISBN 0-8493-1605-7, New York 